\title{
Quantification of Uncertainty in Fire-Weather Forecasts: Some Results of Operational and Experimental Forecasting Programs
}

\author{
Barbara G. BROWN AND AllaN H. MURPHY \\ Department of Atmospheric Sciences, Oregon State University, Corvallis, OR 97331
}

(Manuscript received 19 May 1986, in final form 16 March 1987)

\begin{abstract}
Fire-weather forecasts (FWFs) prepared by National Weather Service (NWS) forecasters on an operational basis are traditionally expressed in categorical terms. However, to make rational and optimal use of such forecasts, fire managers need quantitative information concerning the uncertainty inherent in the forecasts. This paper reports the results of two studies related to the quantification of uncertainty in operational and experimental FWFs.

Evaluation of samples of operational categorical FWFs reveals that these forecasts contain considerable uncertainty. The forecasts also exhibit modest but consistent biases which suggest that the forecasters are influenced by the impacts of the relevant events on fire behavior. These results underscore the need for probabilistic FWFs.

The results of a probabilistic fire-weather forecasting experiment indicate that NWS forecasters are able to make quite reliable and reasonably precise credible interval temperature forecasts. However, the experimental relative humidity and wind speed forecasts exhibit considerable overforecasting and minimal skill. Although somewhat disappointing, these results are not too surprising in view of the fact that (a) the forecasters had little, if any, experience in probability forecasting; (b) no feedback was provided to the forecasters during the experimental period; and (c) the experiment was of quite limited duration. More extensive experimental and operational probability forecasting trials as well as user-oriented studies are required ic enhance the quality of FWFs and to ensure that the forecasts are used in an optimal manner.
\end{abstract}

\section{Introduction}

Future values of weather variables play a key role in many decisions related to fire management. For example, fire-weather forecasts (FWFs) represent an essential input to fire-danger models that are used to evaluate the potential risks of wildfires (Cohen and Deeming, 1985). These forecasts are routinely formulated by National Weather Service (NWS) forecasters for a large number of forest and grassland zones, each represented by a particular ranger station or remote automatic weather station.

To make effective use of weather forecasts, individuals responsible for preventing and/or controlling wildfires need information concerning the uncertainty inherent in the forecasts. Currently, however, fire managers seldom receive explicit information of this type. Specifically, operational FWFs formulated by NWS forecasters are expressed in categorical terms.

Information concerning the uncertainty in FWFs may have a significant impact on decisions made by fire managers. For example, a fire manager given a categor:cal wind speed forecast of $7 \mathrm{mph}$ might make a different decision in the same situation if he or she

\footnotetext{
* Current address and joint affiliation: Environmental and Societal Impacts Group, National Center for Atmospheric Research, Boulder, CO 80307 . The National Center for Atmospheric Research is sponsored by the National Science Foundation.
}

were told, in addition, that the probability of wind speeds exceeding $15 \mathrm{mph}$ was $30 \%$. Moreover, the availability of probabilistic FWFs would allow fre managers to consult a formal procedure such as decision analysis in the process of deciding whether or not to prepare for the possibility of wildfires or to proceed with a prescribed burn (e.g., see Cohan et al., 1984; Radloff and Yancik, 1983; Seaver et al., 1983). Thus, it is quite surprising that issues related to the quantification of uncertainty in FWFs have received relatively little attention (see Murphy and Brown, 1984).

The overall objective of this paper is to quantify the uncertainty in FWFs. In section 2, we briefly describe the specific issues of interest and the approaches and methods used to address these issues. The principal results of the study are presented in sections 3 and 4 . Conclusions and recommendations forthcoming from this work are reported in section 5.

\section{Approæches and methods}

Two specific issues related to the quantification of uncertainty in FWFs are investigated in this paper: (a) the nature and amount of uncertainty in current FWFs and (b) the ability of forecasters to quantify the uncertainty in FWFs in a reliable and skillful manner. The first issue is examined by evaluating operational categorical FWFs and the second issue is addressed by 
conducting and evaluating the results of a probabilistic fre-weather forecasting experiment. Further details concerning these interrelated studies and the methods used to evaluate the respective FWFs are contained in the following two subsections.

\section{a. Operational fire-weather forecasts and their evalu- ation}

\section{1) THe DATA}

The analysis of the uncertainty in operational FWFs is accomplished by evaluating a large number of forecasts and observations archived in the National Fire Weather Data Library (Furman and Brink, 1975). These categorical forecasts are produced by NWS fireweather forecasters each day at approximately 1500 1600 local time (LST). The forecasts are valid the following day at approximately $1400 \mathrm{LST}$, at which time verifying observations are recorded. Thus, the lead time of the forecasts is approximately $24 \mathrm{~h}$.

Forecasts of five weather variables are analyzed, including temperature $(T)$, relative humidity $(R H)$, wind speed (WS), maximum temperature (TMAX), and minimum relative humidity (RHMIN). ${ }^{1}$ RHMIN and TMAX are the minimum relative humidity and maximum temperature, respectively, that occur in the 24$h$ period. $T, R H$, and WS are the values of the variables at the valid time. The forecasts and observations were recorded to the nearest degree Fahrenheit for both $T$ and TMAX, to the nearest $1 \%$ for $\mathrm{RH}$ and RHMIN, and to the nearest mile per hour for WS.

The results reported in this paper are based on data from Black Rock Ranger Station, located in BridgerTeton National Forest in Wyoming at an elevation of $6800 \mathrm{ft}$. These FWFs were formulated by forecasters at the NWS Forecast Office in Boise, Idaho. The dataset includes all forecasts and observations made during the 6-year period 1978-83. However, since most of the forecasts were made during the summer and early fall (i.e., during the fire season) only forecasts and obser. vations from June through October are included in the analysis. In other analyses (not reported here), forecasts and observations from two additional locations were examined and the data from all three locations were divided into two periods to study "seasonal" effects. These more extensive results are presented in Brown and Murphy (1985a).

\section{2) MEASURES OF QUALITY AND UNCERTAINTY}

Measures of quality were selected which would provide information about the uncertainty in the categor-

\footnotetext{
${ }^{1}$ Wind direction is also an important variable in fire-danger modeling. However, the historical data available for wind direction were insufficient to undertake an analysis of the forecasts and observations of this variable.
}

ical forecasts. Specifically, attention is focused on measures that relate directly either to the individual (i.e., marginal) distributions of forecast and observed events or to the conditional distributions of observed events given forecast events. The role of these distributions in forecast verification has recently been discussed by Murphy and Winkler (1987).

The characteristics of individual distributions of forecasts and observations can be summarized by means of box plots (Tukey, 1977; Graedel and Kleiner, 1985). These plots display several quantiles of the distributions and provide a convenient way of comparing pairs or groups of distributions. The length of the box (i.e., the difference between the 0.75 th and the 0.25 th quantiles) in a box plot is a measure of the variability of the distribution. Specifically, this interval contains the middle $50 \%$ of the distribution and its length is called the interquartile range (IQ). In addition, the means and standard deviations of the forecasts and observations represent summary measures of important characteristics of these distributions.

Overall measures of quality such as the mean error (ME), the mean absolute error (MAE), and the rootmean-square error (RMSE) can be used to evaluate the bias and accuracy of the forecasts. In addition, the percentage of forecasts within the correct category [referred to as "percent correct" (PC)]-as well as the percent correct within one category $(\mathrm{PC} \pm 1)$-are potentially useful measures of the accuracy of the forecasts. The widths of the categories used in computing the latter quantities are $5^{\circ} \mathrm{F}$ for $\mathrm{T}$ and TMAX, 5\% for $\mathrm{RH}$ and RHMIN, and $2 \mathrm{mph}$ for WS.

Displays of conditional quantiles of the distributions of observed values given particular forecast values can be used to identify various types of biases and to quantify the uncertainty associated with different forecasts. Such displays generally include running values of several quantiles (e.g., the 0.10 th, 0.25 th, 0.50 th, 0.75 th, and $0.90 \mathrm{th}$ ) of the conditional distributions of observed values given each distinct forecast value. The distances between the 0.75 th and 0.25 th conditional quantiles (the conditional IQ values) provide a means of assessing differences in variability or uncertainty from one forecast to another. The running conditional quantiles are typically smoothed to enhance the ability to detect any trends. One appropriate smoothing technique is hanning (Tukey, 1977), a three-point smoothing algorithm that is equivalent to applying a two-point moving average twice.

\section{b. Experimental fire-weather forecasts and their eval- uation}

\section{1) THE EXPERIMENT}

The fire-weather forecasting experiment involved the formulation of probabilistic FWFs by forecasters at the Boise NWS Forecast Office. These forecasts indicated the likelihood that specific T, WS, and RH events would 
occur at particular times at two locations, including Black Rock Ranger Station in Wyoming. ${ }^{2}$ Only the results for Black Rock are reported here; the results for both locations are described in Brown and Murphy (1985a).

As in the case of operational FWFs, the experimental forecasts were made each day at about 1500 LST, and they were valid the following day at 1400 LST. These experimental FWFs were prepared in addition to the daily operational forecasts. The experiment was initiated on 5 June 1984 and continued until $31 \mathrm{Oc}$ tober 1984. Although 133 experimental forecasts were formulated, the matched set contains only 119 forecasts and observations, due to missing data. Three forecasters made all but one of the forecasts, and they will be referred to as forecasters $\mathrm{A}, \mathrm{B}$, and $\mathrm{C}$ in this paper. These forecasters formulated 30,42 , and 46 experimental forecasts, respectively.

Temperature is a continuous and essentially unbounded variable, and the uncertainty inherent in forecasts of such a variable can be conveniently summarized in terms of credible intervals. In this experiment, each temperature forecast involved the assessment (to the nearest degree Fahrenheit) of the median (T50), lower quartile (T25), and upper quartile (T75) of the forecaster's subjective probability distribution. The interval from T25 to T75, including the endpoints, represents a 50\% central credible interval temperature forecast. An interval of this type is frequently referred to as a variable-width credible interval forecast (see Winkler and Murphy, 1979).

Since wind speed and relative humidity are bounded variables, it is convenient to treat them in terms of sets of overlapping events. Specifically, probability forecasts were formulated for the events WS $>5 \mathrm{mph}$ (WGT5), WS $>10 \mathrm{mph}$ (WGT10), and WS $>15 \mathrm{mph}$ (WGT15), and for the events RH < 40\% (HLT40), RH < 30\% (HLT30), and RH $<20 \%$ (HLT20). The 15 permissible probability values for the wind speed and relative humidity forecasts are $0.00,0.02,0.05,0.10,0.20,0.30$, $0.40,0.50,0.60,0.70,0.80,0.90,0.95,0.98$, and 1.00 .

The forecasters who participated in the experiment were experienced weather forecasters, and they were regular participants in the operational categorical fireweather forecasting program. However, they had relatively little experience in quantifying the uncertainty in their forecasts and they had no experience in quantifying the uncertainty in FWFs. In an effort to overcome this problem, some materials were prepared to aid the forecasters in assessing the probabilities and in checking the consistency of their forecasts, and they were encouraged to make practice forecasts prior to the start of the experiment. No formal feedback was provided to the forecasters during the experimental period.

\footnotetext{
${ }^{2}$ Here a weather "event" is defined as a specific category or interval of values of a weather variable (e.g., $\mathrm{RH}<40 \%$ ).
}

\section{2) VERIFICATION METHODS}

Several different methods and measures are used to evaluate the statistical characteristics and quality of the probability forecasts formulated in the experiment. Since the temperature forecasts differ markedly in form and format from the wind speed and relative humidity forecasts, we discuss the verification methods for these two types of forecasts separately. For a more detailed treatment of these and other methods of evaluating probability forecasts, refer to Murphy and Daan (1984, 1985) and Winkler and Murphy (1979).

In evaluating the quality of the temperature forecasts, it is of some interest to examine the distributions of the forecast temperatures (T25, T50, T75) and observed temperature (TO) and to compare the distribution of T50 with the distribution of TO. For this purpose, statistics such as the mean, median, and standard error of the mean of the respective distributions can be calculated.

The quality of the T50 forecasts as point forecasts can be assessed in several ways. For example, the correlation between T50 and TO can be computed. The overall bias of the T50 forecasts can be evaluated by determining the relative frequency of observed temperatures less than, equal to, and greater than T50 and by computing the ME of T50. Suitable measures of the accuracy of the T50 forecasts include the MAE and RMSE

With regard to the reliability of the $50 \%$ central credible intervals (i.e., the interval from T25 to T75, inclusive), a reasonable approach is to determine the relative frequencies of observed temperatures below, in, and above the intervals, and to compare these relative frequencies with the "theoretical" values (i.e., $0.25,0.50$, and 0.25 ). When these quantities correspond closely, the forecasts are considered to be reliable; otherwise, they are unreliable to some extent. Another important attribute of the credible interval temperature forecasts is their precision, and a natural measure of this attribute is the average width of the intervals.

A composite measure of the reliability and precision of variable-width credible interval forecasts can be obtained by computing the average "loss" associated with the intervals, where the loss represents the average expense incurred by an individual who makes decisions on the basis of the forecasts. A loss function of this type has been described by Winkler and Murphy (1979). In this case, the loss is equal to the width of the interval when the observed temperature falls in the interval and it equals the sum of this width and a "distance" penalty when the observed temperature falls below or above the interval. The asymmetry of the credible interval temperature forecasts can be measured by computing the mean asymmetry (MA) of the intervals,-where MA is defined as the average difference between T50-T25 and T75-T50.

Generally, it is desirable to identify a standard of 
reference against which to compare the characteristics and/or quality of the forecasts of interest. In the case of temperature, climatological data provide this standard of reference. Specifically, the distribution of observed temperatures from the historical database of fireweather observations at Black Rock during the period 1978-83 are used to derive climatological values of the relevant temperature quantiles (i.e., $\mathrm{C} 25, \mathrm{C} 50$, and C75). Treating the climatological values as forecasts, summary measures and measures of quality for climatological forecasts (point values and intervals) can then be computed, and they represent useful standards against which to compare the forecasters' performance.

For wind speed and relative humidity, overall reliability (or bias) can be measured in terms of the difference between the average forecast probability and the observed relative frequency for the particular event. On the other hand, reliability diagrams provide a means of assessing the extent to which specific forecasts (i.e., forecasts of a specific probability value) possess this attribute. In these diagrams, observed relative frequency is plotted against forecast probability for individual probability values. The sample curve joining these points is then compared with the diagonal $45^{\circ}$ line, which represents complete correspondence between forecast probabilities and observed relative frequencies. In judging the significance of departures from this perfect reliability line, it is important to keep in mind that the sampling variability associated with a particular point on the empirical curve is inversely proportional to the square root of the size of the respective sample of forecasts.
A natural measure of the accuracy of probability forecasts for ordinal variables such as wind speed and relative humidity is the ranked probability score (RPS) (Epstein, 1969; Murphy, 1971). In effect, this measure is simply the mean square error of probabilistic forecasts (thus, smaller scores are better). When only a finite number of probability values are used, the RPS can be partitioned into three terms: (a) a term representing the RPS for forecasts based solely on the sample climatological probabilities (RPS SC $_{\text {) }}($ b) a measure of reliability (REL); and (c) a measure of resolution (RES). Specifically, $\mathbb{R P S}=$ RPS $_{\text {SC }}+$ REL - RES. To determine the skill of a sample of forecasts, it is traditional to compare the accuracy of these forecasts with the accuracy of forecasts based on some standard of reference such as climatology. Thus, a natural skill score (SS) in this context is SS $=100\left[1-\left(\mathrm{RPS} / \mathrm{RPS}_{\mathrm{SC}}\right)\right]$ $=100\left[(\mathrm{RES}-\mathrm{REL}) / \mathrm{RPS}_{\mathrm{SC}}\right]$. This skill score represents the improvement (in percent) in the accuracy of the forecasts of interest over the accuracy of forecasts based on sample climatology.

\section{Uncertainty in operational fire-weather forecasts \\ a. Some results}

Box plots showing the characteristics of the distributions of operational forecasts and observations are presented in Fig. 1. The shapes of these plots indicate that some of the distributions are skewed (i.e., they do not have a symmetric shape). In particular, the distributions of forecast and observed RH, WS, and RHMIN appear positively skewed, with heavy upper tails. That
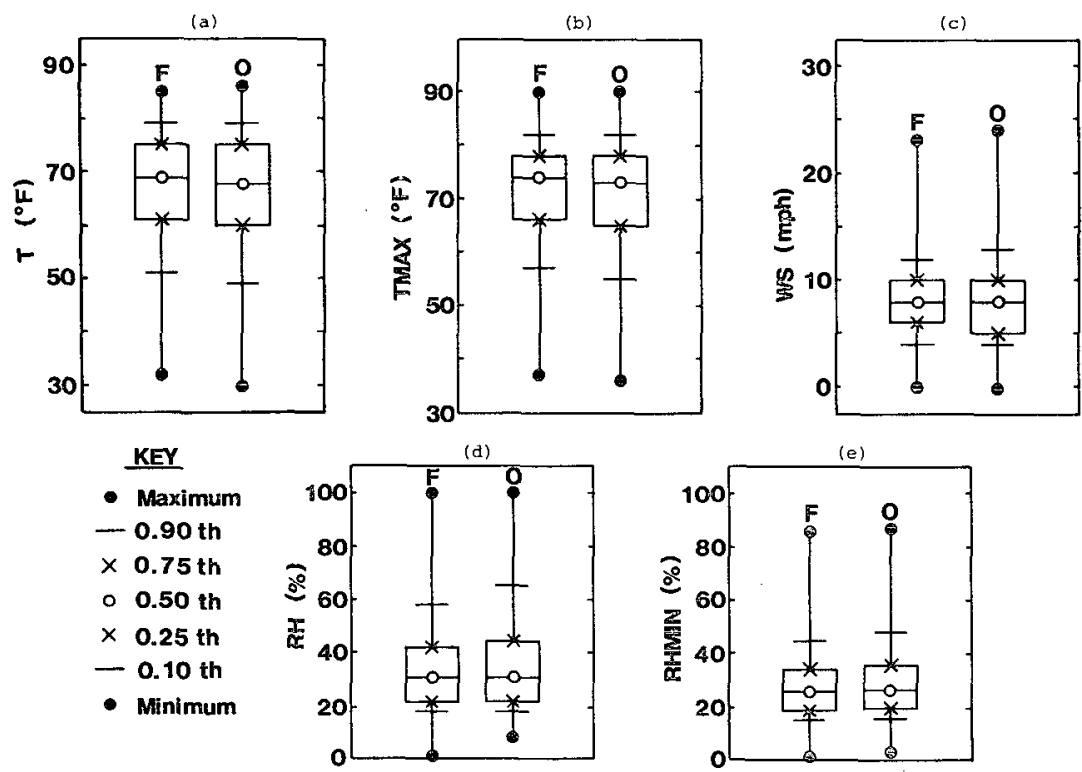

FIG. 1. Box plots of distributions of forecasts $(\mathrm{F})$ and observations $(\mathrm{O})$ for operational fireweather forecasts at Black Rock for (a) temperature (T), (b) maximum temperature (TMAX), (c) wind speed (WS), (d) relative humidity (RH), and (e) minimum relative humidity (RHMIN). 
is, most of the forecast and observed values of these variables are small, with the exception of a few much larger values. The sizes of the boxes are generally slightly smaller for the distributions of forecasts than for the distributions of observations, indicating that the former are somewhat less variable than the latter. This difference is particularly noticeable for WS, but it exists for the other variables as well. Overall, the forecast distributions exhibit little bias.

More specific information regarding the statistical characteristics of the forecasts and observations is contained in Table 1. The standard deviations in Table 1 also indicate that the forecasts have somewhat tighter distributions than the observations. For example, the standard deviation of observed $\mathrm{RH}$ is $19.7 \%$, whereas the standard deviation of forecast $\mathrm{RH}$ is $16.5 \%$. This relationship holds consistently for all five variables.

Positive bias (ME) appears to exist for T, WS, and TMAX (i.e., the mean forecast value is larger than the mean observed value), whereas the RH and RHMIN forecasts appear to be negatively biased. Forecasts of these variables for the other locations and time periods are also consistently biased in this manner (Brown and Murphy, 1985a).

Comparison of the MAE and RMSE values indicates that the forecast errors in $\mathrm{T}$ and $\mathrm{RH}$ are generally larger than the corresponding errors in TMAX and RHMIN. The $P C$ and $P C \pm 1$ values follow a similar (but inverse) pattern. That is, the values of these statistics are larger for TMAX and RHMIN than they are for T and RH, respectively.

Figure 2 contains conditional 0.10 th, 0.25 th, 0.50 th, 0.75 th, and 0.90 th running quantiles of the distributions of observed values given specific forecast values for the five variables. For example, the median observed temperature for all forecasts of $60^{\circ} \mathrm{F}$ is approximately $62^{\circ} \mathrm{F}$ (Fig. 2a). These running quantiles have been smoothed using hanning (Tukey, 1977).

Figure $2 \mathrm{a}$ reveals that the $\mathrm{T}$ forecasts are relatively unbiased. A decrease in variability (i.e., increase in accuracy) with increasing forecast $T$ is also apparent, as indicated by the decrease in conditional IQ as forecast $T$ increases. For example, the conditional IQ value for a forecast of $55^{\circ} \mathrm{F}$ is approximately $8^{\circ} \mathrm{F}$, whereas IQ is less than $5^{\circ} \mathrm{F}$ for a forecast of $80^{\circ} \mathrm{F}$. Thus, it appears that forecasts of high temperatures are somewhat more accurate than forecasts of low temperatures.

Conditional RH quantiles (Fig. 2b) indicate that 1) the forecasts are somewhat biased for both low and high values of forecast $\mathrm{RH}$, with negative bias at the low end and positive bias at the high end, and 2) the variability of observed RH increases with increasing forecast RH. In fact, the variability of observed RH is quite low for forecast values less than $20 \%$ and extremely high for forecast values greater than $20 \%$, with the conditional IQ value almost reaching $50 \%$ for forecast RH between 70 and $80 \%$.

Examination of the WS conditional quantiles (Fig. $2 c)$ suggests that only a weak relationship exists between the forecast and observed values of this variable. The conditional medians and quantiles of observed WS increase only slightly with increasing forecast WS. Moreover, the forecasts are negatively biased for low WS and positively biased for high WS. Little or no relationship exists between forecast WS and the variability of observed WS.

Conditional quantile plots of TMAX (Fig. 2d) indicate that these forecasts are quite accurate, with the conditional IQ values being less than $12^{\circ} \mathrm{F}$ in all cases. The shape of the median curve for RHMIN (Fig. 2e) suggests that small RHMIN forecasts are somewhat negatively biased and large RHMIN forecasts are somewhat positively biased. In addition, the variability of observed RHMIN increases noticeably with increases in forecast RHMIN. However, the spread in this variable (as represented by IQ and the differences between the 0.90th and 0.10th quantiles) is less than that for RH (Fig. 2b).

TABLE 1. Summary table containing statistics of distributions of forecasts and observations and basic measures of forecast quality for operational forecasts. ME is mean error; MAE mean absolute error; RMSE root-mean-square error; PC percent correct; and PC \pm 1 percent correct within one category. For definitions of categories used in determining $P C$ and $P C \pm 1$, refer to section $2 \mathrm{a}$.

\begin{tabular}{|c|c|c|c|c|c|c|c|c|c|c|}
\hline Variable & Type & $\begin{array}{c}\text { Sample } \\
\text { size }\end{array}$ & Mean & Median & $\begin{array}{l}\text { Standard } \\
\text { deviation }\end{array}$ & ME & MAE & RMSE & $\begin{array}{l}\mathrm{PC} \\
(\%)\end{array}$ & $\underset{(\%)}{P C \pm 1}$ \\
\hline$T\left({ }^{\circ} \mathrm{F}\right)$ & $\begin{array}{l}\text { Forecast } \\
\text { Observed }\end{array}$ & $\begin{array}{l}661 \\
661\end{array}$ & $\begin{array}{l}66.9 \\
66.0\end{array}$ & $\begin{array}{l}69 \\
68\end{array}$ & $\begin{array}{l}10.8 \\
11.5\end{array}$ & 0.94 & 4.4 & 6.1 & 37.7 & 82.8 \\
\hline RH (\%) & $\begin{array}{l}\text { Forecast } \\
\text { Observed }\end{array}$ & $\begin{array}{l}661 \\
661\end{array}$ & $\begin{array}{l}34.3 \\
36.1\end{array}$ & $\begin{array}{l}31 \\
31\end{array}$ & $\begin{array}{l}16.5 \\
19.7\end{array}$ & -1.84 & 11.8 & 16.1 & 19.2 & 49.9 \\
\hline WS (mph) & $\begin{array}{l}\text { Forecast } \\
\text { Observed }\end{array}$ & $\begin{array}{l}661 \\
661\end{array}$ & $\begin{array}{l}8.1 \\
8.0\end{array}$ & $\begin{array}{l}8 \\
8\end{array}$ & $\begin{array}{l}3.2 \\
3.7\end{array}$ & 0.14 & 3.1 & 4.0 & 23.3 & 57.3 \\
\hline $\operatorname{TMAX}\left({ }^{\circ} \mathbf{F}\right)$ & $\begin{array}{l}\text { Forecast } \\
\text { Observed }\end{array}$ & $\begin{array}{l}661 \\
661\end{array}$ & $\begin{array}{l}71.5 \\
70.6\end{array}$ & $\begin{array}{l}74 \\
73\end{array}$ & $\begin{array}{r}9.8 \\
10.4\end{array}$ & 0.90 & 3.7 & 5.4 & 46.0 & 85.8 \\
\hline RHMIN (\%) & $\begin{array}{l}\text { Forecast } \\
\text { Observed }\end{array}$ & $\begin{array}{l}660 \\
658\end{array}$ & $\begin{array}{l}28.1 \\
29.8\end{array}$ & $\begin{array}{l}26 \\
27\end{array}$ & $\begin{array}{l}12.6 \\
14.0\end{array}$ & -1.66 & 8.1 & 11.3 & 23.1 & 60.6 \\
\hline
\end{tabular}



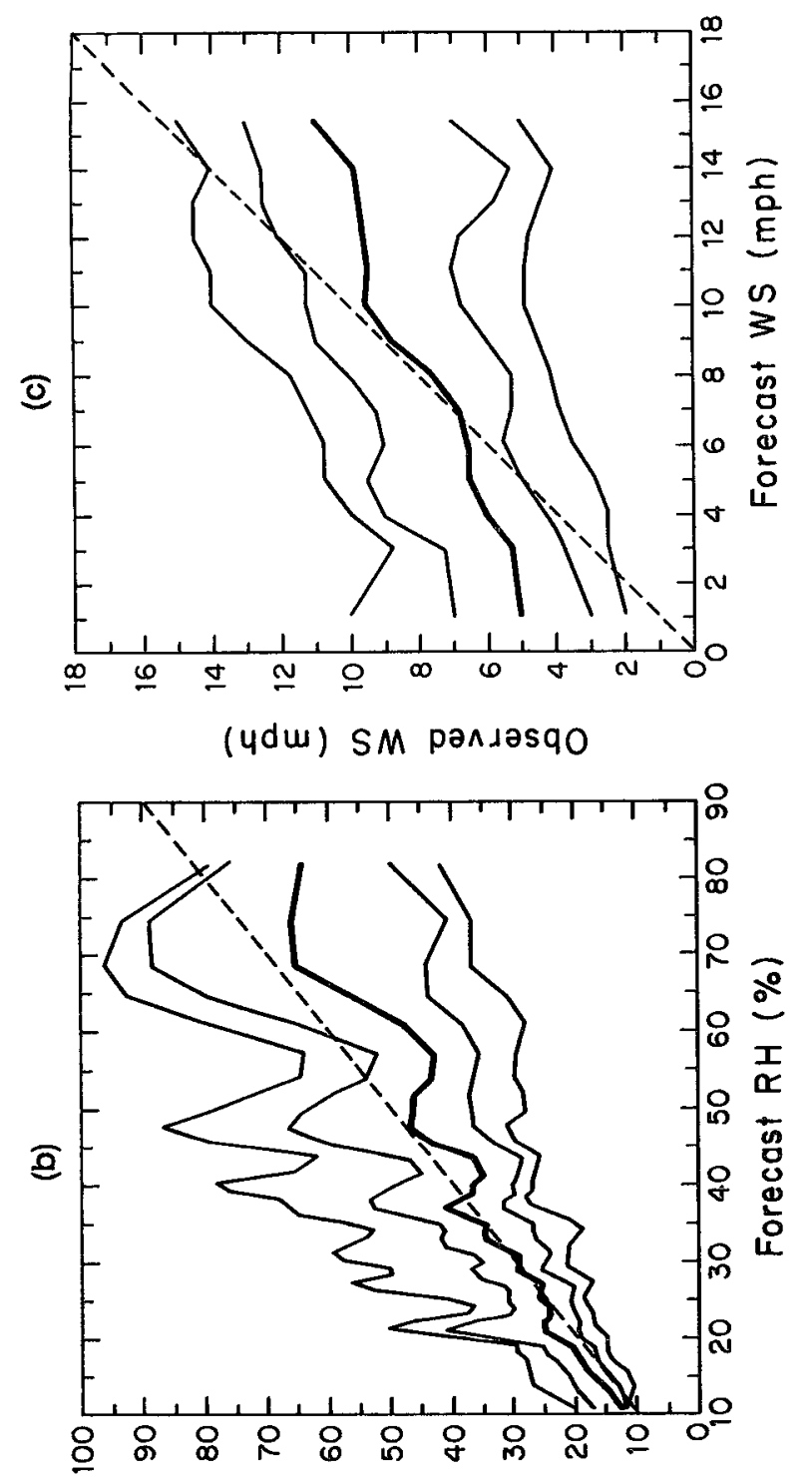

(\%) Hy pansasqo
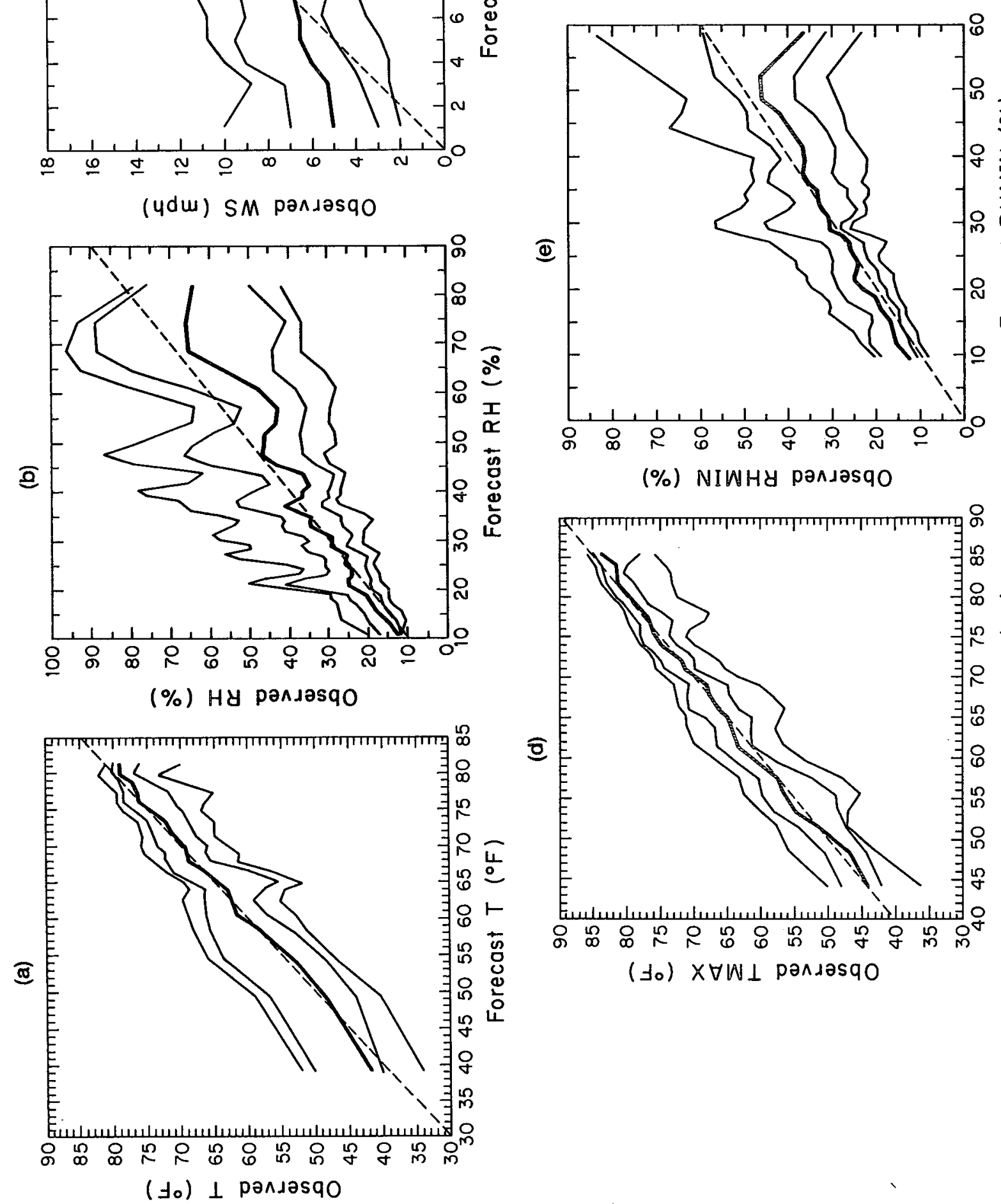

(\%) NIWHY pənsəsqO

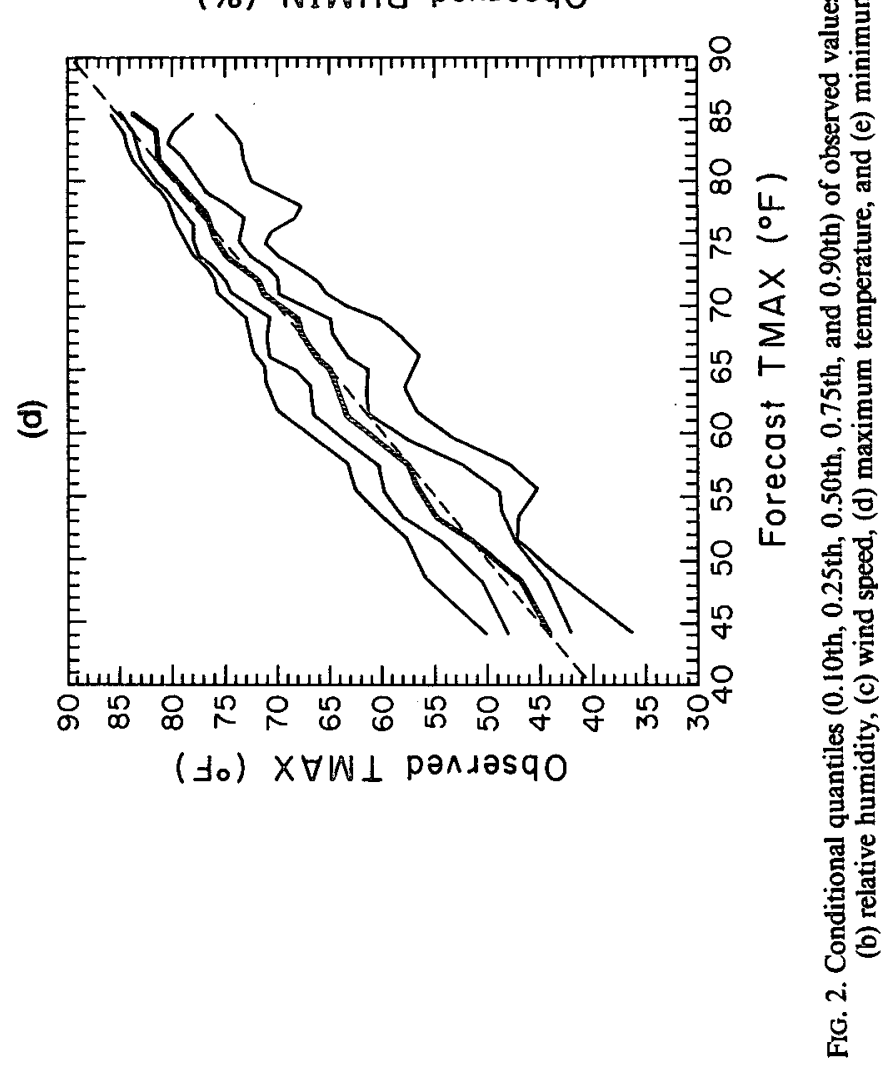




\section{b. Discussion}

The results presented in section $3 \mathrm{a}$ reveal several important and interesting characteristics of the operational FWFs. In general, the results suggest that a large amount of uncertainty is associated with these forecasts and that the forecasts are biased to some extent. Very similar results were obtained for the other two locations and time periods (Brown and Murphy, 1985a).

Box plots of the distributions of forecasts and observations (Fig. 1) indicate that the observations are somewhat more variable than the forecasts, which is a common characteristic of many weather forecasts and observations. In this case, however, the differences in variability may be due in part to the manner in which the forecasts are formulated. Specifically, forecasters at the Boise NWS Forecast Office formulate their FWFs as trend forecasts. Thus, it is possible that the forecasters underestimate day-to-day changes in the weather; they may anchor too strongly on current conditions in preparing their forecasts.

The overall biases (ME) in the FWFs suggest that a predictable "value-induced" bias exists in these forecasts (see Murphy and Daan, 1984). For example, positive biases in the T and TMAX forecasts reflect the importance of high temperatures in contributing to fire danger. Similarly, high wind speeds have a significant impact on fire danger and fire behavior, and low relative humidities are of particular importance in determining fire danger. Thus, the forecasters might, on average, underforecast RH and RHMIN and overforecast T, TMAX, and WS, in order to provide conservative forecasts as input to the fire-danger models. This result should be of interest to those individuals who use FWFs or the output of fire-danger rating system models in making fire-management decisions. In view of the biases associated with the weather forecast inputs to these models, fire danger may be overestimated to some extent.

Differences in accuracy between T and TMAX and between RH and RHMIN may arise in part because of the different temporal definitions of the events associated with the two types of variables. Specifically, the T and RH forecasts are verified at a particular point in time, whereas the TMAX and RHMIN forecasts are verified over a $24-\mathrm{h}$ period.

The conditional quantile results (Fig. 2) indicate that the forecasts of all variables except WS tend to be more accurate at one extreme of the forecast range than at the other extreme. For example, the uncertainty in observed RH increases with increasing values of forecast RH. Similar results hold for RHMIN. In the case of $T$, the observations exhibit somewhat less uncertainty for forecasts of high temperatures.

At least three possible explanations of this variability in forecast accuracy and uncertainty can be identified. First, the ranges of forecast and observed values may be bounded, either numerically or physically. For ex- ample, RH and RHMIN must fall between 0 and $100 \%$. On the other hand, $\mathrm{T}$ may be bounded by physical factors that depend on the location and/or season. Such bounds may enable the forecasters to make more accurate forecasts for extreme values, since the potential size of the error is limited.

Secondly, the greater accuracy of high temperature and low relative humidity forecasts may be related to the persistence of the summertime high pressure patterns associated with these conditions in Wyoming. In contrast, the frontal passages associated with the occurrence of low temperatures and high relative humidities are relatively difficult to forecast. ${ }^{3}$

A third possible explanation for the greater accuracy of the forecasts for extreme values could involve a tendency for the forecasters to concentrate on providing more accurate forecasts of such values, since forest fire danger increases with high temperatures and low relative humidities. It is not unreasonable to assume that the forecasters may have been most concerned withand expended the most effort in making forecasts forthese extreme values and thus succeeded in forecasting such extremes with greater accuracy. In summary, a combination of boundedness, persistence, and special attention to providing accurate forecasts of the extremes may explain this characteristic of the quality and uncertainty of operational FWFs.

\section{Verification of experimental probabilistic fire- weather forecasts}

In section 3 , the overall uncertainty in operational FWFs was quantified indirectly by evaluating the quality of these categorical forecasts. Here we report the results of a probabilistic fire-weather forecasting experiment designed to evaluate the ability of NWS forecasters to quantify directly the uncertainty in their FWFs.

\section{a. Some results}

Since the temperature forecasts differ markedly in form from those for wind speed and relative humidity, we discuss the results for these two types of experimental forecasts separately.

\section{1) TEMPERATURE}

Summary statistics for the observed temperatures (TO) and temperature quantile forecasts are presented in Table 2. The mean values of TO are quite similar among forecasters. However, the mean T50 values are greater than or equal to the mean TO values in all cases. In addition, the standard errors of T50 are all less than or equal to the standard errors of TO.

\footnotetext{
${ }^{3}$ This explanation was suggested by a perceptive reviewer.
} 
TABLE 2. Statistics of observed temperatures and temperature quantiles (all in ${ }^{\circ} \mathrm{F}$ ) for experimental forecasts. SE is standard error.

\begin{tabular}{|c|c|c|c|c|c|c|}
\hline \multirow[b]{2}{*}{ Forecaster } & \multirow{2}{*}{$\begin{array}{c}\text { Sample } \\
\text { size }\end{array}$} & \multirow[b]{2}{*}{ Statistic } & \multirow{2}{*}{$\begin{array}{c}\text { Observed } \\
\text { temperature } \\
\text { TO }\end{array}$} & \multicolumn{3}{|c|}{ Temperature quantiles } \\
\hline & & & & T25 & T50 & $\mathrm{T} 75$ \\
\hline All & 119 & $\begin{array}{c}\text { Mean } \\
\text { Median } \\
\text { SE }\end{array}$ & $\begin{array}{c}61.8 \\
66 \\
1.3\end{array}$ & $\begin{array}{l}59.4 \\
63 \\
1.2\end{array}$ & $\begin{array}{c}63.2 \\
68 \\
1.2\end{array}$ & $\begin{array}{c}67.3 \\
71 \\
1.2\end{array}$ \\
\hline A & 30 & $\begin{array}{l}\text { Mean } \\
\text { Median } \\
\text { SE }\end{array}$ & $\begin{array}{l}61.5 \\
68 \\
2.8\end{array}$ & $\begin{array}{l}61.4 \\
66 \\
2.5\end{array}$ & $\begin{array}{c}63.6 \\
69 \\
2.5\end{array}$ & $\begin{array}{c}67.3 \\
72 \\
2.4\end{array}$ \\
\hline $\mathbf{B}$ & 42 & $\begin{array}{l}\text { Mean } \\
\text { Median } \\
\text { SE }\end{array}$ & $\begin{array}{r}62.8 \\
65.5 \\
1.8\end{array}$ & $\begin{array}{l}60.1 \\
62 \\
1.6\end{array}$ & $\begin{array}{l}65.1 \\
67 \\
1.6\end{array}$ & $\begin{array}{l}70.4 \\
72 \\
1.5\end{array}$ \\
\hline $\mathrm{C}$ & 46 & $\begin{array}{l}\text { Mean } \\
\text { Median } \\
\text { SE }\end{array}$ & $\begin{array}{l}61.9 \\
66 \\
2.2\end{array}$ & $\begin{array}{c}58.2 \\
62 \\
2.2\end{array}$ & $\begin{array}{r}61.9 \\
66.5 \\
2.2\end{array}$ & $\begin{array}{r}65.2 \\
70.5 \\
2.2\end{array}$ \\
\hline
\end{tabular}

Although primary interest here is focused on the temperature intervals as indicators of the uncertainty in the forecasts, we first consider the T50 values as point forecasts (Table 3 ). In particular, the correlation coefficients relating T50 and TO are indicative of fairly strong agreement between the forecasts and observations. However, it also appears that the T50 values exhibit a moderate bias toward overforecasting (ME $=1.4^{\circ} \mathrm{F}$ ). Among the individual forecasters, forecaster C's T50 values are most accurate.

The climatological temperature values are $\mathrm{C} 25$ $=60^{\circ} \mathrm{F}, \mathrm{C} 50=68^{\circ} \mathrm{F}$, and $\mathrm{C} 75=75^{\circ} \mathrm{F}$. The quality of $\mathrm{C} 50$ as a forecast is evaluated by comparing it to the values of TO for all forecasters combined, as well as for the individual forecasters. As shown in Table 3, the C50 forecasts exhibit a strong positive bias and are much less accurate than the T50 forecasts. Specifically, for all forecasters combined, C50 has a ME of about $6^{\circ} \mathrm{F}$ and a MAE more than twice that for T50 (greater than $10^{\circ} \mathrm{F}$ versus $4-5^{\circ} \mathrm{F}$ ).

The distributions of errors for T50 and C50 are depicted in Fig. 3. As indicated by these box plots, the errors in both types of forecasts tend to be skewed toward positive values. In addition, the spread in the distribution of errors for $\mathbb{T} 50$ generally is considerably less than the corresponding spread for C50. The distribution of errors for $\mathrm{C} 50$ can be viewed as an indicator of the "difficulty" of the forecasting situation (with a larger spread indicating greater difficulty), and it can be used as a standard of reference to evaluate the performance of the individual forecasters. In this regard, the distribution of errors for T50 for forecaster $\mathrm{C}$ is considerably narrower than the corresponding distribution for C50, whereas forecaster B's distribution of errors has roughly the same spread as the corresponding distribution for C50.

TABLE 3. Measures of performance of median temperatures for experimental forecasts, and relative frequencies of observed temperatures less than, equal to, and greater than median temperature forecasts. TM = median temperature forecast (equals T50 for forecasters and C50 for climatology); CC is correlation coefficient; ME mean error; MAE mean absolute error; and RMSE root-mean-square error. Sample sizes are the same as in Table 2.

\begin{tabular}{|c|c|c|c|c|c|c|c|}
\hline \multirow[b]{2}{*}{ Forecaster } & \multirow[b]{2}{*}{$\mathrm{CC}$} & \multirow[b]{2}{*}{$\begin{array}{l}\text { ME } \\
\left({ }^{\circ} \mathrm{F}\right)\end{array}$} & \multirow[b]{2}{*}{$\begin{array}{c}\text { MAE } \\
\left({ }^{\circ} \mathrm{F}\right)\end{array}$} & \multirow[b]{2}{*}{$\begin{array}{c}\text { RMSE } \\
\left({ }^{\circ} F\right)\end{array}$} & \multicolumn{3}{|c|}{ Relative frequency } \\
\hline & & & & & $\mathrm{TO}<\mathrm{TM}$ & $\mathrm{TO}=\mathrm{TM}$ & $\mathrm{TO}>\mathrm{TM}$ \\
\hline \multicolumn{8}{|c|}{ Forecasters } \\
\hline $\begin{array}{c}\text { All } \\
\text { A } \\
\text { B } \\
\text { C }\end{array}$ & $\begin{array}{l}0.92 \\
0.93 \\
0.80 \\
0.97\end{array}$ & $\begin{array}{l}1.4 \\
2.0 \\
2.3 \\
0.0\end{array}$ & $\begin{array}{l}4.1 \\
4.5 \\
5.2 \\
2.7\end{array}$ & $\begin{array}{l}5.8 \\
6.0 \\
7.3 \\
3.5\end{array}$ & $\begin{array}{l}0.571 \\
0.633 \\
0.667 \\
0.435\end{array}$ & $\begin{array}{l}0.067 \\
0.067 \\
0.024 \\
0.109\end{array}$ & $\begin{array}{l}0.361 \\
0.300 \\
0.310 \\
0.457\end{array}$ \\
\hline \multicolumn{8}{|c|}{ Climatology } \\
\hline $\begin{array}{c}\text { All } \\
\text { A } \\
\text { B } \\
\text { C }\end{array}$ & - & $\begin{array}{l}6.2 \\
6.5 \\
5.2 \\
.6 .1\end{array}$ & $\begin{array}{r}10.4 \\
11.1 \\
8.9 \\
10.5\end{array}$ & $\begin{array}{l}15.3 \\
16.4 \\
12.5 \\
15.7\end{array}$ & $\begin{array}{l}0.529 \\
0.467 \\
0.572 \\
0.522\end{array}$ & $\begin{array}{l}0.076 \\
0.066 \\
0.071 \\
0.087\end{array}$ & $\begin{array}{l}0.395 \\
0.467 \\
0.357 \\
0.391\end{array}$ \\
\hline
\end{tabular}




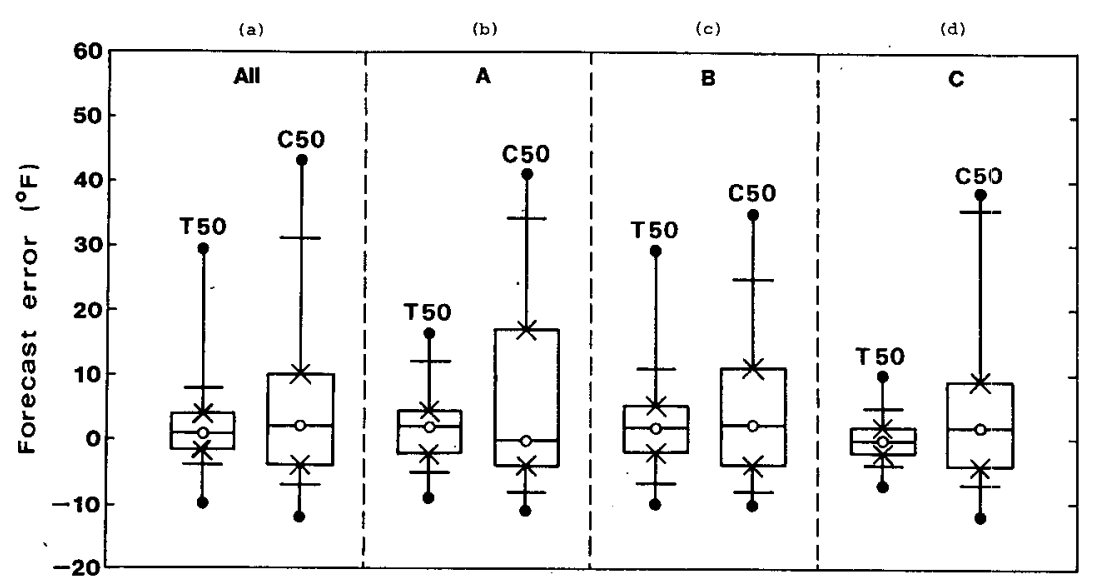

FIG. 3. Box plots of errors in T50 and C50 forecasts for (a) all forecasters combined, (b) forecaster A, (c) forecaster B, and (d) forecaster C.

Table 3 also contains quantitative information concerning the bias (overforecasting/underforecasting) in $\mathrm{T} 50$ and $\mathrm{C} 50$. In particular, the relative frequencies indicate that considerable overforecasting exists for all forecasters combined, for forecasters A and B, and for climatology except for forecaster $A$. That is, the relative frequencies of TO $<$ T50 and/or TO $<$ C50 in these cases are greater than 0.500 .

The relative frequencies of observed temperatures below, in, and above the forecast and climatological intervals (Table 4) characterize the reliability of the credible intervals. As indicated by these relative frequencies, the intervals assessed by the forecasters and climatology are, on the average, too wide (forecaster C's forecasts are particularly noteworthy in this respect). Comparison of the relative frequencies reveals that, overall, the climatological interval is more reliable than the forecasters' intervals. On the other hand, the forecasters' intervals and the climatological interval are both consistently "placed" too high; that is, the relative frequencies below the intervals exceed the relative frequencies above the intervals.

Comparison of the average width of the forecasters' intervals (approximately $9^{\circ} \mathrm{F}$ ) and the width of the climatological interval $\left(16^{\circ} \mathrm{F}\right)$ indicates that the forecasters' intervals were considerably more precise than the climatological interval, on the average. Forecaster B's intervals tended to be less precise than the other two forecasters' intervals, yet the variability of interval width is less for forecaster $B$ than for forecasters $A$ and C. In this regard, forecaster $B$ used an $11^{\circ} \mathrm{F}$-wide interval (T50 $\left.\pm 5^{\circ} \mathrm{F}\right)$ on most of his forecasting occasions.

Statistics (mean and standard error) of the loss function reveal that the average loss associated with fore-

TABLE 4. Relative frequencies of observed temperatures below, in, and above $50 \%$ central credible interval forecasts; mean and standard error (SE) of width of intervals; loss function; and average asymmetry (MA) for experimental forecasts. Note that TL and TU are the lower and upper quartile forecasts, respectively $(\mathrm{TL}=\mathrm{T} 25$ and $\mathrm{TU}=\mathrm{T} 75$ for forecasters; $\mathrm{TL}=\mathrm{C} 25$ and $\mathrm{TU}=\mathrm{C} 75$ for climatology). Sample sizes are the same as in Table 2.

\begin{tabular}{|c|c|c|c|c|c|c|}
\hline \multirow[b]{2}{*}{ Forecaster } & \multicolumn{3}{|c|}{ Relative frequency } & \multirow{2}{*}{$\frac{\text { Interval width }}{\begin{array}{c}\text { Mean (SE) } \\
\left({ }^{\circ} \mathrm{F}\right)\end{array}}$} & \multirow{2}{*}{$\frac{\text { Loss function }}{\begin{array}{c}\text { Mean (SE) } \\
\left({ }^{\circ} \mathrm{F}\right)\end{array}}$} & \multirow{2}{*}{ 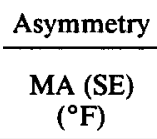 } \\
\hline & $\mathrm{TO}<\mathrm{TL}$ & $\mathrm{TL} \leqslant \mathrm{TO} \leqslant \mathrm{TU}$ & $\mathrm{TO}>\mathrm{TU}$ & & & \\
\hline \multicolumn{7}{|c|}{ Forecasters } \\
\hline $\begin{array}{l}\text { All } \\
\text { A } \\
\text { B } \\
\text { C }\end{array}$ & $\begin{array}{l}0.235 \\
0.367 \\
0.262 \\
0.109\end{array}$ & $\begin{array}{l}0.655 \\
0.533 \\
0.619 \\
0.783\end{array}$ & $\begin{array}{l}0.109 \\
0.100 \\
0.119 \\
0.109\end{array}$ & $\begin{array}{r}8.9(0.2) \\
6.9(0.3) \\
11.3(0.2) \\
8.0(0.3)\end{array}$ & $\begin{array}{l}14.7(1.2) \\
16.0(2.6) \\
18.7(2.6) \\
10.1(0.7)\end{array}$ & $\begin{array}{r}-0.29(0.19) \\
-1.57(0.36) \\
-0.24(0.26) \\
0.43(0.29)\end{array}$ \\
\hline \multicolumn{7}{|c|}{ Climatology } \\
\hline $\begin{array}{l}\text { All } \\
\text { A } \\
\text { B } \\
\text { C }\end{array}$ & $\begin{array}{l}0.311 \\
0.333 \\
0.310 \\
0.283\end{array}$ & $\begin{array}{l}0.605 \\
0.567 \\
0.595 \\
0.652\end{array}$ & $\begin{array}{l}0.084 \\
0.100 \\
0.095 \\
0.065\end{array}$ & $\begin{array}{l}16 \\
16 \\
16 \\
16\end{array}$ & $\begin{array}{l}36.7(3.5) \\
39.9(7.5) \\
31.1(4.4) \\
37.0(6.0)\end{array}$ & $\begin{array}{l}1 \\
1 \\
1 \\
1\end{array}$ \\
\hline
\end{tabular}


TABLE 5. Average forecast probability, observed relative frequency, and overall reliability for experimental wind speed forecasts. Sample sizes are the same as in Table 2.

\begin{tabular}{|c|c|c|c|c|c|c|c|c|c|}
\hline \multirow[b]{2}{*}{ Forecaster } & \multicolumn{3}{|c|}{$\begin{array}{l}\text { Average forecast probability } \\
\text { (standard error) }\end{array}$} & \multicolumn{3}{|c|}{ Observed relative frequency } & \multicolumn{3}{|c|}{ Overall reliability } \\
\hline & WGT5 & WGT10 & WGT15 & WGT5 & WGT10 & WGT15 & WGT5 & WGT10 & WGT15 \\
\hline All & $\begin{array}{c}0.598 \\
(0.017)\end{array}$ & $\begin{array}{c}0.308 \\
(0.015)\end{array}$ & $\begin{array}{c}0.126 \\
(0.012)\end{array}$ & 0.613 & 0.101 & 0.025 & -0.015 & 0.207 & 0.101 \\
\hline A & $\begin{array}{c}0.460 \\
(0.037)\end{array}$ & $\begin{array}{c}0.222 \\
(0.030)\end{array}$ & $\begin{array}{c}0.080 \\
(0.015)\end{array}$ & 0.667 & 0.100 & 0.033 & -0.207 & 0.122 & 0.047 \\
\hline B & $\begin{array}{c}0.633 \\
(0.024)\end{array}$ & $\begin{array}{c}0.410 \\
(0.023)\end{array}$ & $\begin{array}{c}0.215 \\
(0.023)\end{array}$ & 0.548 & 0.095 & 0.045 & 0.085 & 0.315 & 0.167 \\
\hline $\mathrm{C}$ & $\begin{array}{c}0.652 \\
(0.024)\end{array}$ & $\begin{array}{c}0.265 \\
(0.019)\end{array}$ & $\begin{array}{c}0.071 \\
(0.012)\end{array}$ & 0.652 & 0.109 & 0.000 & 0.000 & 0.156 & 0.071 \\
\hline
\end{tabular}

caster B's intervals exceeds the average losses associated with the other two forecasters' intervals. Moreover, the losses corresponding to the climatological interval are more than twice as large as the losses corresponding to the forecasters' intervals (with the exception of forecaster B). The values of MA indicate that, overall, the forecasters' intervals are moderately asymmetric, with forecaster A's forecasts being the most asymmetric and forecaster B's forecasts being the most symmetric.

\section{2) WIND SPEED AND RELATIVE HUMIDITY}

The average forecast probabilities for the wind speed (relative humidity) events increase from WGT15 to WGT 10 to WGT5 (HLT20 to HLT30 to HLT40), as shown in Tables 5 and 6 . Observed relative frequencies of these events follow the same ordering. The overall reliability values in Tables 5 and 6 indicate that overforecasting occurs for all events except for WGT5, the only event with relative frequency greater than onehalf. Considerable variability in bias exists among forecasters and events. Forecaster $B$ exhibits the greatest tendency toward overforecasting, with this tendency being especially pronounced for the relative humidity events.
The reliability diagram for the WGT5 forecasts (Fig. 4a) indicates that these forecasts are fairly reliable. However, the WGT10 and WGT 15 forecasts (Figs. 4b and $4 \mathrm{c}$ ) and the relative humidity forecasts (Fig. 5) exhibit considerable overforecasting for all probability values. This overforecasting, which tends to increase as the sample relative frequency of the event decreases, is particularly noticeable for HLT20 (Fig. 5a)-an event that never occurred in the experiment. The frequency-of-use distributions for both the wind speed and relative humidity forecasts (Figs. 4 and 5) tend to reflect the differences in sample relative frequencies of the events. Moreover, the range of probability values used tends to decrease as the sample relative frequency decreases.

The wind speed skill scores (Table 7) are negative for all forecasters except forecaster C. For example, for all forecasters combined, forecasts based solely on sample climatological probabilities are $22 \%$ more accurate than the experimental forecasts. These results reflect the relatively large values of REL and the relatively small values of RES. For relative humidity, the skill of the forecasts for all forecasters combined is strongly negative (Table 7). Forecaster B's extremely low skill score is due primarily to the very large value

TABLE 6. Average forecast probability, observed relative frequency, and overall reliability for experimental relative humidity forecasts. Sample sizes are the same as in Table 2.

\begin{tabular}{|c|c|c|c|c|c|c|c|c|c|}
\hline \multirow[b]{2}{*}{ Forecaster } & \multicolumn{3}{|c|}{$\begin{array}{l}\text { Average forecast probability } \\
\text { (standard error) }\end{array}$} & \multicolumn{3}{|c|}{ Observed relative frequency } & \multicolumn{3}{|c|}{ Overall reliability } \\
\hline & HLT20 & HLT30 & HLT40 & HLT20 & HLT30 & HLT40 & HLT20 & HLT30 & HLT40 \\
\hline All & $\begin{array}{c}0.098 \\
(0.012)\end{array}$ & $\begin{array}{c}0.229 \\
(0.017)\end{array}$ & $\begin{array}{c}0.439 \\
(0.023)\end{array}$ & 0.000 & 0.025 & 0.202 & 0.098 & 0.204 & 0.237 \\
\hline A & $\begin{array}{c}0.073 \\
(0.012)\end{array}$ & $\begin{array}{c}0.182 \\
(0.027)\end{array}$ & $\begin{array}{c}0.407 \\
(0.037)\end{array}$ & 0.000 & 0.033 & 0.267 & 0.073 & 0.149 & 0.140 \\
\hline B & $\begin{array}{c}0.174 \\
(0.026)\end{array}$ & $\begin{array}{c}0.338 \\
(0.030)\end{array}$ & $\begin{array}{c}0.540 \\
(0.032)\end{array}$ & 0.000 & 0.024 & 0.143 & 0.174 & 0.314 & 0.397 \\
\hline $\mathrm{C}$ & $\begin{array}{c}0.048 \\
(0.011)\end{array}$ & $\begin{array}{c}0.162 \\
(0.024)\end{array}$ & $\begin{array}{c}0.366 \\
(0.042)\end{array}$ & 0.000 & 0.022 & 0.217 & 0.048 & 0.140 & 0.149 \\
\hline
\end{tabular}



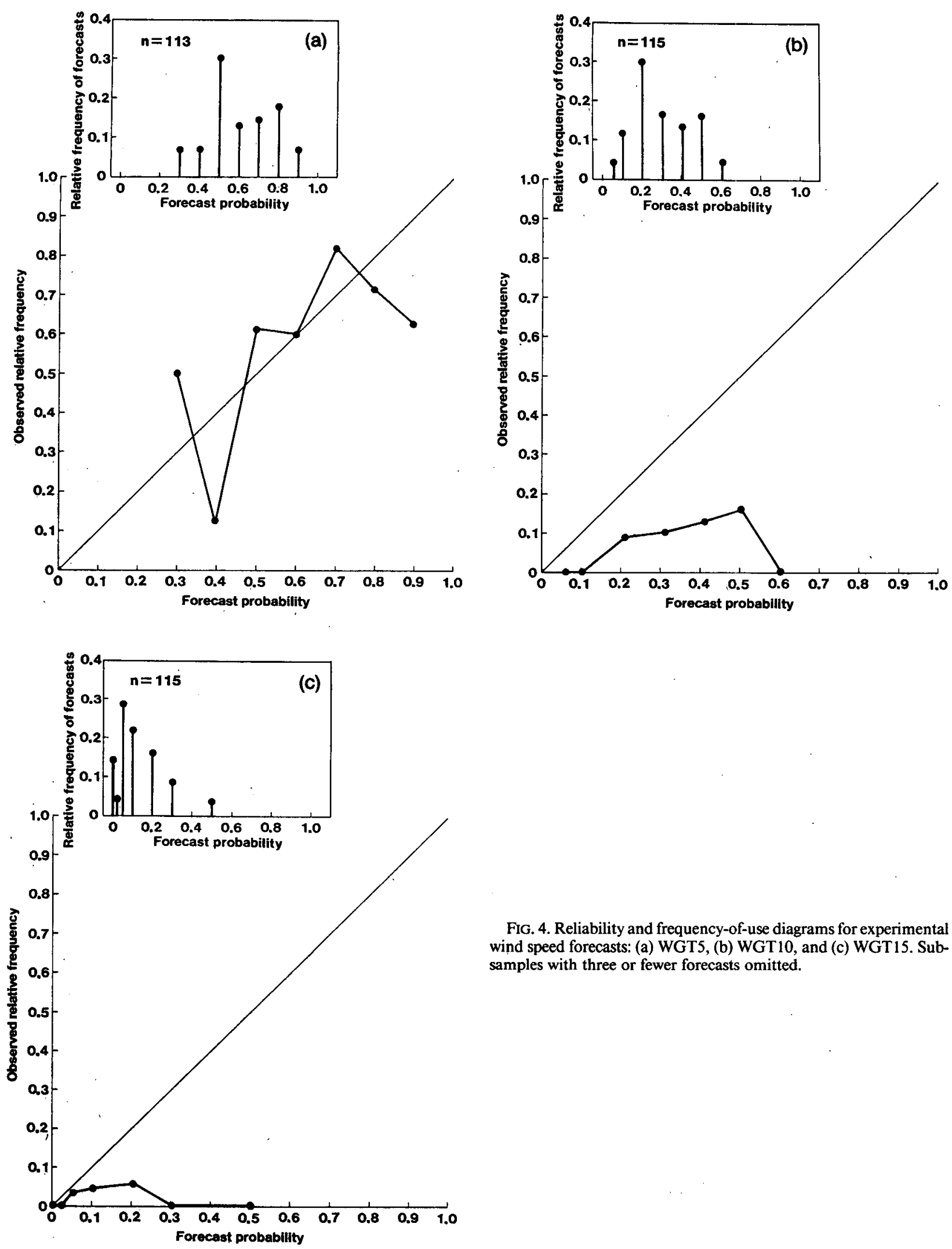

FIG. 4. Reliability and frequency-of-use diagrams for experimental wind speed forecasts: (a) WGT5, (b) WGT10, and (c) WGT15. Subsamples with three or fewer forecasts omitted. 

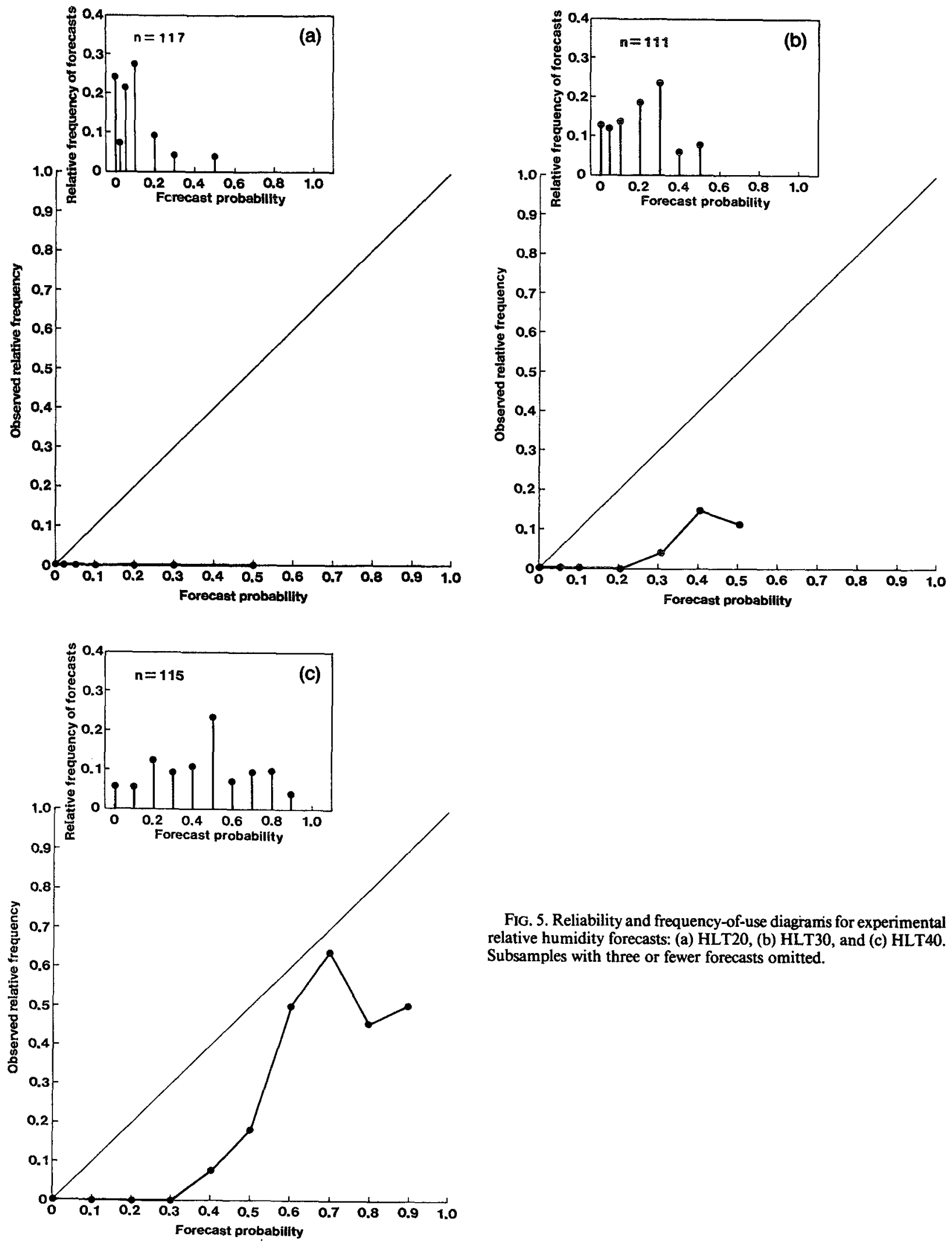

FIG. 5. Reliability and frequency-of-use diagrams for experimental relative humidity forecasts: (a) HLT20, (b) HLT30, and (c) HLT40. Subsamples with three or fewer forecasts omitted. 


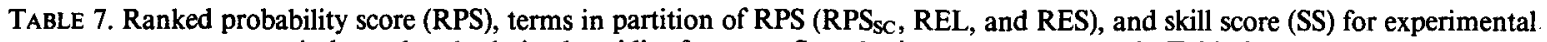
wind speed and relative humidity forecasts. Sample sizes are the same as in Table 2.

\begin{tabular}{|c|c|c|c|c|c|}
\hline$\underline{\text { Forecaster }}$ & $\mathrm{RPS}_{\mathrm{SC}}$ & REL & RES & RPS & $\begin{array}{l}\text { SS } \\
(\%)\end{array}$ \\
\hline \multicolumn{6}{|c|}{ Wind speed } \\
\hline $\begin{array}{c}\text { All } \\
\text { A } \\
\text { B } \\
\text { C }\end{array}$ & $\begin{array}{l}0.3523 \\
0.3444 \\
0.3792 \\
0.3237\end{array}$ & $\begin{array}{l}0.2495 \\
0.2555 \\
0.4115 \\
0.2181\end{array}$ & $\begin{array}{l}0.1721 \\
0.2233 \\
0.2221 \\
0.2187\end{array}$ & $\begin{array}{l}0.4297 \\
0.3766 \\
0.5686 \\
0.3232\end{array}$ & $\begin{array}{r}-22.0 \\
-9.4 \\
-50.0 \\
0.2\end{array}$ \\
\hline \multicolumn{6}{|c|}{ Relative humidity } \\
\hline $\begin{array}{c}\text { All } \\
\text { A } \\
\text { B } \\
\text { C }\end{array}$ & $\begin{array}{l}0.1856 \\
0.2278 \\
0.1457 \\
0.1914\end{array}$ & $\begin{array}{l}0.2458 \\
0.1756 \\
0.4360 \\
0.2090\end{array}$ & $\begin{array}{l}0.1262 \\
0.1944 \\
0.1015 \\
0.1914\end{array}$ & $\begin{array}{l}0.3051 \\
0.2089 \\
0.4802 \\
0.2090\end{array}$ & $\begin{array}{r}-64.4 \\
8.2 \\
-229.6 \\
-9.2\end{array}$ \\
\hline
\end{tabular}

of REL (the value of RES is also relatively small). Only forecaster A exhibits modest positive skill for the relative humidity forecasts.

\section{b. Discussion}

Since we are primarily concerned here with the ability of the forecasters to assess the uncertainty in their forecasts, it is the accuracy, reliability, and skill of the experimental probabilistic forecasts that are of particular interest. In the case of the temperature forecasts, attention necessarily focuses on the reliability and precision of the $50 \%$ central credible intervals and their quality relative to that of the climatological interval.

The relative frequencies of observed temperatures falling in the forecasters' $50 \%$ credible intervals generally exceeded the expected probability value (i.e., 0.50 ), thereby indicating that the forecast intervals were too wide, overall. The climatological interval revealed a similar tendency to be too wide, although this tendency was not as pronounced as it was for the forecasters' intervals. On the other hand, the climatological interval was generally "placed" too high, implying that the temperatures in the experimental period were below normal (i.e., they were, on average, lower than the temperatures in the period used to determine the climatological values). This fact may have contributed to the tendency for the forecasters' intervals to be placed too high as well. Overall, the forecasters' intervals and the climatological interval appear to be of roughly equal reliability.

With regard to the precision of the temperature forecasts, the average width of the forecasters' intervals was only slightly more than one-half the width of the climatological interval. Moreover, the loss valuesbased on a loss function which is a composite measure of reliability and precision-were more than twice as large for the climatological interval as they were for the forecasters' intervals. In summary, the forecasters' $50 \%$ central credible interval forecasts appear to be as reliable as, and considerably more precise than, the climatological interval.
Evidently, forecaster B's method of choosing intervals equal to $T 50 \pm 5^{\circ} \mathrm{F}$ on almost every occasion was not successful. In particular, forecaster B's interval forecasts exhibited the lowest precision and the highest loss among the three forecasters. In addition, the T50 forecasts produced by forecaster $B$ had the greatest bias and the least skill relative to climatology. The practice of ignoring day-to-day variations in uncertainty is apparently a suboptimal strategy.

The ability of NWS forecasters to quantify the uncertainty in their temperature forecasts in terms of credible intervals has been investigated in two previous experiments (Murphy and Winkler, 1974; Winkler and Murphy, 1979). In these experiments, forecasters at the Denver and Milwaukee NWS Forecast Offices assessed $50 \%$ and $75 \%$ central credible intervals for maximum and minimum temperatures. For the $50 \%$ credible intervals for maximum temperature (i.e., the forecasts corresponding most closely to the forecasts formulated in the probabilistic fire-weather forecasting experiment), the reliability of the forecasts was quite good, with only a slight tendency for the observed relative frequency of temperatures in the intervals to exceed the theoretical probability of this event. (This observed relative frequency was 0.515 at Denver and 0.579 at Milwaukee.) In fact, the forecasters' intervals were more reliable than the corresponding climatological intervals. Moreover, the average width of the forecasters' intervals was only about one-third of the average width of the climatological intervals.

It is clear that the credible interval temperature forecasts formulated in the Denver and Milwaukee experiments were more reliable and more precise than those formulated in the fire-weather experiment. In addition to the obvious difficulties inherent in comparing the results of experiments involving different locations and time periods, two other factors may have contributed to these differences in performance. First, the forecasters at Denver and Milwaukee all had considerable probability forecasting experience in conjunction with the operational public precipitation forecasting pro- 
gram (although they had no experience in credible interval temperature forecasting). Second, in the earlier experiments, the forecasts were formulated for nearby locations in relatively flat terrain for which routine, high-quality observations had been available for many years. In the fire-weather experiment, on the other hand, the forecasts were prepared for remote locations in relatively complex terrain for which a much smaller and less reliable set of observations was available.

In the case of wind speed and relative humidity, attention is focused on the reliability and skill of the forecasts. In an overall sense, the experimental forecasts tended to overforecast most events. With regard to reliability, forecasts of WGT5 were fairly reliable; this event occurred relatively frequently. Otherwise, the forecasts generally exhibited overforecasting for all probability values, and the range of probability values used decreased as the climatological probability decreased. Relative overforecasting tended to increase with decreasing climatological probability and with increasing "severity" of the event in terms of its impact on fire danger. For example, the amount of overforecasting of WGT15 is much greater than the amount of overforecasting of WGT5 (cf. Figs. 4a and 4c). This result suggests the possible existence of a value-induced bias toward the overforecasting of events that are related to high levels of fire danger. In addition, of course, it is more difficult to make reliable probabilistic forecasts for events that occur relatively infrequently.

The measures of skill indicate that, in an overall sense, the forecasters exhibited negative skill for all events. This relatively poor performance was due largely to the lack of reliability of the probabilistic forecasts. In this regard, the reliability of such forecasts would be expected to improve as the forecasters gained additional experience in expressing their uncertainty in quantitative terms. In addition, the use of sample climatology rather than historical climatology as a standard of reference tends to underestimate the skill of forecasts (i.e., sample climatology generally leads to a lower-that is, poorer-skill score; see Murphy, 1974).

The results of a related "spot" fire-weather forecasting experiment (Brown and Murphy, 1985b) were quite similar to those presented here. In that experiment, which was also conducted in the summer of 1984, NWS forecasters formulated short-term (1-2 hour) probabilistic forecasts of temperature, relative humidity, wind speed, and wind direction. These forecasts are called spot forecasts because they are prepared for different locations and time periods on each occasion. The skill scores for relative humidity and wind speed forecasts formulated in the spot experiment were also negative.

Several possible explanations for the negative skill scores in these experiments can be identified. First, the forecasters had little experience in quantifying the uncertainty in their fire-weather forecasts, and they had no experience in formulating probability forecasts of the variables included in the experiment. In addition, the forecasters were not provided with any formal feedback during the course of the experiment, and they thus were unable to adjust their forecasts to take into account any tendencies toward overforecasting or underforecasting. As noted in the following paragraph, such feedback can have a significant impact on the reliability and skill of probabilistic forecasts. Characteristics of the experiment and the forecasting situation may also have contributed to the negative skill scores and poor reliability of the experimental forecasts. For example, the forecasts were prepared for remote locations in complex terrain, and the sample sizes were relatively small.

Several probability forecasting experiments have been undertaken in which forecasts similar in form and format to the wind speed and relative humidity forecasts have been formulated. These experiments include a probabilistic tornado forecasting experiment conducted at the NWS National Severe Storms Forecast Center (Murphy and Winkler, 1982), an experiment involving probabilistic forecasts of wind speed, visibility, and precipitation events at Zierikzee in The Netherlands (Daan and Murphy, 1982; Murphy and Daan, 1984), and a probabilistic quantitative precipitation forecasting (QPF) experiment at San Antonio, Texas (Murphy et al., 1985). It should be emphasized that these experiments involved different events and different lead times than those of concern in the fireweather forecasting experiment. Nevertheless, the results of these experiments all revealed considerable overforecasting for events with relatively low climatological probabilities, with the amount of overforecasting tending to increase as the climatological probability decreased. The skill of these forecasts ranged from substantial positive values for very short-range (e.g., 0-6 hour) wind speed and visibility forecasts at Zierikzee to small positive or even negative values for events with low climatological probabilities and/or for forecasts with longer lead times (e.g., 24-30 hours). In the Zierikzee and QPF experiments, the forecasters were provided with feedback regarding their individual and collective performance at the end of the first year. Results from the second year of the experiments indicated modest to marked increases in the forecasters' absolute and/or relative performance. These results suggest that feedback and additional experience might lead to noticeable improvements in subsequent probabilistic fire-weather forecasting experiments.

\section{Conclusions and recommendations}

The results of the study of the quality of operational fire-weather forecasts lead to several important conclusions regarding the current practice of formulating and expressing these forecasts in categorical terms. First, the amount of uncertainty in the forecasts (as indicated, for example, by the conditional distributions 
of the observations given the forecasts) is such that it appears essential to provide users with information regarding this ubiquitous feature of the forecasts. Decisions based on taking these categorical forecasts at face value will generally be suboptimal. The systematic biases in the fire-weather forecasts, as well as the tendency for these forecasts to underestimate the variability in the observed events, also have important implications for the mode of expression of the forecasts. Both of these characteristics may be due in part to the impacts (as perceived by the forecasters) of the weather events-and thus the forecasts-on fire behavior. Only when forecasts are expressed in probabilistic terms is it possible to disentangle the forecasting and decisionmaking tasks and therefore to make unbiased forecasts an unquestionably desirable goal.

Moreover, even under ideal circumstances (i.e., in the absence of biases), an ex post evaluation such as that presented in section 3 can only provide a crude measure of the overall uncertainty in the forecasts. Hence, since the uncertainty in fire-weather forecasts undoubtedly varies from situation to situation; information derived from an ex post approach may be quite misleading when used as input to specific decisions on particular occasions. As a result, we believe that this approach represents a relatively unsatisfactory alternative to the ex ante approach in which a forecaster (or a model) directly assesses the uncertainty associated with each forecast and expresses the forecasts in probabilistic terms.

The results of the probabilistic fire-weather forecasting experiment indicate, however, that the forecasters achieved only limited success in quantifying the uncertainty in their fire-weather forecasts. Although these results are disappointing, they are not too surprising in view of the "conditions" under which the forecasts were formulated-that is, lack of experience in quantifying forecast uncertainty, the absence of objective guidance information (e.g., climatological probabilities, objective forecasts) and feedback, the location of forecast sites in complex terrain, and the short duration of the experiment. Such conditions have contributed to less than entirely successful results in several other probability forecasting programs (e.g., Daan and Murphy, 1982; Ivarsson et al., 1986; Murphy et al., 1985; Murphy and Winkler, 1982).

In conclusion, information regarding the uncertainty in fire-weather forecasts is required by fire managers (and others) in order to make rational and optimal decisions. However, the results reported here reveal that additional experimental work will be required before weather forecasters are able to provide fire managers with reliable and skillful probabilistic forecasts on an operational basis. In fact, we believe that a holistic approach to the problem of increasing the quality and utility of fire-weather forecasts requires an integrated program of forecasting and user-oriented studies.

These studies should include a training program for forecasters in which they would gain experience in quantifying the uncertainty in their FWFs and in using verification data to diagnose and improve forecasting performance; an applied research program to develop, test, and implement guidance procedures; and operational forecasting trials at several locations for at least one fire season. It will also be necessary to survey potential forecast users to determine the specific weather events for which probabilistic FWFs are required. In addition, educational programs will be needed to provide such individuals with information and instructional material regarding the interpretation and use of probabilistic forecasts. Only then would it be appropriate to implement an operational probabilistic fireweather forecasting program, complemented by ongoing studies to facilitate the effective utilization of the forecasts. Such a program will allow fire managers to make decisions under uncertainty that are more nearly optimal in the sense of minimizing the losses and costs associated with the management of prescribed burns and wildfires.

Acknowledgments. Many individuals made important contributions to this study of the uncertainty in fire-weather forecasts. First and foremost, we would like to thank the National Weather Service (NWS) forecasters at Boise, Idaho for their assistance and cooperation in the probabilistic fire-weather forecasting experiment. We would also like to express our appreciation to Clyde O'Dell and William Parker, both of the NWS, for their help in organizing and designing this experiment. The analysis of the database containing operational categorical fire-weather forecasts was greatly facilitated by the assistance of Glen Brink and David Radloff of the USDA Forest Service. Finally, we thank two anonymous reviewers for their helpful comments on an earlier version of this paper.

This research was supported by the USDA Forest Service under Contract 28-K3-302 with the Rocky Mountain Forest and Range Experiment Station.

\section{REFERENCES}

Brown, B. G., and A. H. Murphy, 1985a: Quantification of uncertainty in operational and experimental fire-danger forecasts. Oregon State University, Department of Atmospheric Sciences, SCIL Rep. 85-1, 220 pp.

- and $-1985 \mathrm{~b}$ : Verification of experimental probabilistic spot fire-weather forecasts. Oregon State University, Department of Atmospheric Sciences, SCIL Rep. 85-2, 66 pp.

Cohan, D., S. M. Haas, D. L. Radloff and R. F. Yancik, 1984: Using fire in forest management: Decision making under uncertainty. Interfaces, 14, 8-19.

Cohen, J. D., and J. E. Deeming, 1985: The National Fire-Danger Rating System: Basic equations. USDA, Forest Service, Pacific Southwest Forest and Range Experiment Station, General Technical Rep. PSW-82, 16 pp.

Daan, H., and A. H. Murphy, 1982: Subjective probability forecasting in The Netherlands: Some operational and experimental results. Meteor. Rundsch., 35, 99-112.

Epstein, E. S., 1969: A scoring system for probability forecasts of ranked categories. J. Appl. Meteor., 8, 985-987. 
Furman, R. W., and G. E. Brink, 1975: The National Fire Weather Data Library: What it is and how to use it. USDA, Forest Service, Rocky Mountain Forest and Range Experiment Station, General Technical Rep. RM-19, 8 pp.

Graedel, T. E., and B. Kleiner, 1985: Exploratory analysis of atmospheric data. Probability, Statistics, and Decision Making in the Atmospheric Sciences. A. H. Murphy and R. W. Katz, Eds., Westview Press, 1-43.

Ivarsson, K.-I., R. Joelsson, E. Liljas and A. H. Murphy, 1986: Probability forecasting in Sweden: Some results of experimental and operational programs at the Swedish Meteorological and Hydrological Institute. Wea. Forecasting, 1, 136-154.

Murphy, A. H., 1971: A note on the ranked probability score. $J$. Appl. Meteor., 10, 155-156.

- 1974: A sample skill score for probability forecasts. Mon. Wea. Rev., 102, 48-55.

weather forecasting. Oregon State University, Department of Atmospheric Sciences, SCIL Rep. 84-2, 53 pp.

- , and H. Daan, 1984: Impacts of feedback and experience on the quality of subjective probability forecasts: Comparison of results from the first and second years of the Zierikzee experiment. Mon. Wea. Rev., 112, 413-423.

- , and -, 1985: Forecast evaluation. Probability, Statistics, and Decision Making in the Atmospheric Sciences. A. H. Murphy and R. W. Katz, Eds., Westview Press, 379-437.

-, and R. L. Winkler, 1974: Credible interval temperature forecasts: Some experimental results. Mon. Wea. Rev., 102, 784794.

$\longrightarrow$, and — 1982: Subjective probabilistic tornado forecasts: Some experimental results. Mon. Wea. Rev., 110, 1288-1297.

- , and - 1987: A general framework for forecast verification. Mon. Wea. Rev., 115, 1330-1338.

—, W.-R. Hsu, R. L. Winkler and D. S. Wilks, 1985: The use of probabilities in subjective quantitative precipitation forecasts: Some experimental results. Mon. Wea. Rev., 耳13, 2075-2089.

Radloff, D. L., and R. F. Yancik, 1983: Decision analysis of prescribed burning. Preprints of the Seventh Conf. on Fire and Forest Meteorology, Fort Collins, Amer. Meteor. Soc., 85-89.

Seaver, D. A., P. J. Roussopoulos and A. N. S. Freeling, 1983: The escaped fire situation: A decision analysis approach. USDA, Forest Service, Rocky Mountain Forest and Range Experiment Station, Research Paper RM-244, 12 pp.

Tukey, J. W., 1977: Exploratory Data Analysis. Addison-Wesley, $688 \mathrm{pp}$.

Winkler, R. L., and A. H. Murphy, 1979: The use of probabilities in forecasts of maximum and minimum temperatures. Meteor. Mag., 108, 317-329. 